\title{
Addressing the dilemma of India's state dependency on Alcohol: 'New-Soft' Paternalism approach
}

\author{
Shivakumar Jolad ${ }^{*}$ and Chaitanya Ravi** \\ *Associate Professor of Public Policy, ${ }^{* *}$ Assistant Professor of Public Policy at FLAME \\ University, Pune,-411021, INDIA
}

\begin{abstract}
Indian states have alcohol policies ranging from strict prohibition to high taxation and overregulation. A pernicious effect of prohibition in particular has been the clogging of judiciary, disproportionate impacts on the poor and marginalized and diversion of already limited state capacities. In this article, we examine the role of state policy in India in addressing alcoholism's deleterious impacts such as economic hardships, domestic violence and high disease burden. We have traced the current policy ambivalence to India's history with attitudes ranging from permissiveness, colonial-era commodification to prohibition. We argue that India's current alcohol policy can be understood as a combination of 'old' paternalism built on moral-religious ideas and 'hard' paternalism where the state interference overrides conscious choice of individual agent. We propose a 'new-soft,' postcolonial framework which strikes a balance between individual choice, public health, gender parity and state revenues while eschewing disproportionate prosecution and punishment.
\end{abstract}

Keywords: India's Alcohol Policy, Alcohol taxation, Alcohol and health, Paternalism, Libertarianism.

Funding: This research received no specific grant from any funding agency in the public, commercial, or not-for-profit sectors.

Conflict of Interest: The Authors declare that there is no conflict of interest. 


\section{Introduction}

The Covid-19 pandemic has brought major economies around the world including India's to a level of anaemic activity not witnessed since the Great Depression. The ad-hoc opening of liquor stores in May, in the middle of a raging pandemic (Times of India, 2020, May 6) and strict lockdown has renewed the debate on the role of the State in regulating alcohol sale and use, excise duties, improvement of public health, enhancement of gender parity, respect for individual choice and promotion of a moderate drinking culture. The Indian state's current alcohol policies tend to navigate between raising alcohol revenues and curbing deleterious effects of alcohol through a suite of policies including excessive taxation, over regulation (protectionism) and outright prohibition. India's non-prohibition states have adopted an ambivalent 'permit but don't promote' approach, in which they benefit from alcohol sales through high-taxes even as they are careful to not actively and openly promote alcohol.

Major states continue to derive as much as $15 \%$ of their revenues from alcohol excise duties (Sharma, 2020), a continuation of the "lock-in" effect of colonial-era state policies that commodified alcohol. High excise duties interact with a peculiar, price inelastic drinking culture characterized by India's preference for hard liquors (30\% spirits and $30 \%$ country liquor), even as it is already the world's second largest consumer of spirits (Ambekar et al., 2019 ) .Further, India is the world's third largest liquor market valued at \$35 billion in 2017 (Kashyap, 2017), and is expected to grow to $\$ 39.7$ billion by 2024 at a Combined Average Growth Rate (CAGR) of 7.4\% (Goldstein Research, 2020).

Harmful use of alcohol claims 3 million deaths worldwide and the WHO's Executive Board meeting in February 2020 unanimously identified global alcoholism as a 'public health priority' requiring 'accelerated action.' According to the World Health Organization's (WHO) status report on Alcohol and Public Health 2018, India loses a colossal 260,000 people to alcohol, making it a major public health problem (WHO, 2019). Substantial sections of the population suffer from chronic alcoholism or consume alcohol in a harmful manner, requiring medical intervention.

Alcohol consumption tends to aggravate India's social stratifications with women accounting for a very small proportion of alcohol consumption while suffering the brunt of its 
consequences due to lowering of a key threshold for domestic violence and diversion of family income to fuel male alcoholism. India's hard liquor (and excessive) drinking culture and expanding liquor market may increase the risk of domestic violence. Hard liquor drinking preferences and a growing liquor market also risks exacerbating caste inequalities in sociallystratified India by increasing the disease burden on poor and low caste communities who consume cheaper country liquor. To complicate matters further, redressal mechanisms for justice for the poor (usually lower caste) are painfully slow with high pendency rates in prohibition states such as Gujarat and Bihar adversely affecting even minor offenders.

Thus, Indian policymakers are challenged to come up with a policy that reduces the adverse public health outcomes for poor, lower-caste men and women, and domestic abuse on women, without trampling on cultural practices and infringing on individual autonomy to make choices. Such a policy will also continue to remain constrained by the state-dependence on excise duties as a major source of revenue.

This paper begins with a brief but systematic analysis of the various historical, moral and economic factors that influence the Indian state's perception of alcohol and its current policies. We find that India's alcohol policies remain constrained by particular version of British extractive colonialism that commodified alcohol and the religio-moral values of conservative puritanism held dear by its independence movement. We argue that India's alcohol policies can be understood as largely paternalistic in nature with deep state intrusions into individual sovereignty to both garner windfall revenues through high taxation and to use the same high rates as deterrents to high consumption. The high excise duties, when combined with overzealous prosecution of the poor and marginalized, both for producing illicit liquor in prohibition and non-prohibition states in courts with long pendency periods, fall under the 'hard' side of the paternalistic spectrum. Hard paternalism also coincides with 'old' paternalism which aims to make people conform consistently to "religious or moralistic notions of goodness" held by policymakers (Rizzo and Whitman, 2009) as evidenced by total prohibition in three Indian states.

This article problematizes the 'old-hard' paternalistic policies of the Indian state predicated on punitive taxation, and proposes 'new-soft' paternalistic policies. New paternalism involves less state intrusion into individual autonomy and aims to improve individual/public welfare 
by their own standards rather than those imposed top-down by the state (Thomas and Buckmaster, 2010).

The rest of the article is divided into five parts:

1) A detailed review of existing alcohol policies, current pattern of consumption, public health implications of alcohol abuse and domestic violence, and geography of alcohol regulation as in prohibition versus non-prohibition states

2) A brief systematic review of various influences (colonial commodification, colonial bureaucratization, and religio-moral values) on India's current alcohol policies

3) Classification of existing alcohol policies into hard (colonialism, path dependent excise duties) versus old (conservative puritanism of Indian nationalist movement)

4) Inadequacy of current policies-inability to promote moderate drinking culture, excessive state control, and sub-optimal public health outcomes; and the need for a pragmatic policy approach balancing people's choice and protecting their interests including autonomy.

5) A set of recommendations- which including soft paternalist approaches such as tax rationalization to shift drinking patterns from hard to low-alcohol content liquors rather, nudging through innovative social messaging campaigns and design changes, decommodification of alcohol, and judicial and sectoral reforms.

\section{India's alcohol-addicted states}

The Reserve Bank of India (RBI) report on state budget shows that during 2018-19,the Indians States and Union Territories collected Rs. 1.51 trillion ( $\$ 19.89$ billion) from excise duty on liquor (Reserve Bank of India, 2019). The excise revenue from liquor accounts for 10-15 per cent of the revenue of states like Uttar Pradesh (UP), Karnataka, and Maharashtra. In the lockdown period, banking on the people's insatiable thirst for alcohol, states including Delhi, UP, Kerala, and Karnataka hiked taxes on alcohol, to fill their coffers. Further, the rate of taxation is high across all three major categories of alcoholic drinks (beers, wines and spirits) with widely varying levels of alcohol.

In Maharashtra for example, the excise duty is $300 \%$ on Indian Made Foreign Liquor (IMFLspirits) including brandy, whisky, rum and vodka among others with a high alcohol content of $42 \%$ by volume. Drinks such as beer with low alcohol content $(5-8 \%)$ are also taxed at a 
relatively high $175-235 \%$ while wines (12-15\%) are taxed from between 100-200\% depending on the place of origin and blending (Government of Maharashtra Excise Department, 2019). The only exception made in case of wines is for grapes grown within the state without the addition of alcohol. Even country liquor (apart from cashew and Mahua flower-based liquors) is taxed at a whopping $213 \%$ of manufacturing cost.

\section{India's consumption pattern and growth}

The WHO defines the Alcohol per capita (APC) consumption as the total alcohol per capita consumed by persons aged 15 or older within a calendar year in litres of pure alcohol. According to WHO's Global Status report on alcohol and health, India's APC has more than doubled from 2.4 litres per capita in 2005 to 5.7 litres in 2016 (World Health Organization, 2019). Compared to the European nations (9.8 litres), India's per capita consumption is lower largely due to a lesser fraction of drinkers. However, Indians that do drink are heavy drinkers with the consumption level at a high 14.7 litres, most of which is distilled spirits (14.6 litres). The stark gender disparity in drinking is clear from the wide gulf between India's male (9.4 litres) and female (1.7 litres) APC.

\section{Alcohol consumption- A male preoccupation}

A recent National Substance Use Survey in India led by All India Institute of Medical Sciences (AlIMS), New Delhi (Ambekar et al., 2019), in 2019 showed that 14.6\% of the national population aged from 10-70 years drank Alcohol. There is substantial gender disparity in the overall percentage of male and female drinking. Only $1.6 \%$ of women drink alcohol, compared with $27.3 \%$ of men, and about one in five alcohol-using men suffer from alcohol dependence, whereas in women it is one in sixteen. Even if reporting inhibitions on the part of women were to be factored in, the aforementioned level of disparity is large. Even more worryingly, $1.3 \%$ of children between 10-17 years consume alcohol. Indians are predominantly high spirit drinkers with Country liquor (30\%), and Spirits (30\%) being the most consumed hard liquors. 
By global comparison, India is the second-largest consumer of spirits (whiskey, vodka, gin, rum, tequila, liqueurs), behind China, and the largest consumer of Whisky in the world, accounting for half of global consumption (Global Health Observatory, 2020). This hard-liquor dependence has profound implications for health spending on alcohol-related ailments by families, domestic violence, alcohol-related work impairment and road safety. In comparison to heavy consumption of spirits, beer (21\%) and wine (4\%) consumption is low although its taxation rate is high, as explained earlier.

\section{Heavy Drinking Habits}

The strong preference among Indian drinkers for high alcohol-concentration drinks is further aggravated by their heavy drinking habits. The Substance Use Study-2019, further points out ( $p$ p 14) around $43 \%$ of consumers have more than four drinks in a single sitting. This dangerous habit is categorized as 'Heavy Episodic Drinking' and it places drinkers at an elevated risk for chronic health ailments (Ambekar et al., 2019). A substantial proportion of alcohol consumers (26.8\%) also risk getting involved in physical altercations after drinking, indulge in risky 'day time consumption of alcohol' (21.2\%), and are at a greater risk of road traffic accidents (4.1\%) when driving under the influence. Overall, a staggering $2.7 \%$ (29 million individuals) of India's population suffers from the deleterious consequences of acute alcohol dependence while an even more worrying $5.2 \%$ of people across age ranges (10-75 years) partake of alcohol in a harmful or dependent pattern, requiring counseling or medical intervention.

Regional studies on heavy alcohol consumption indicate (a) culture of heavy daily drinking among lower and lower-middle sections of the society, especially in liquor shops (Gupta et.al. , 2003 ) (b) widespread belief that alcohol carries benefits for health and well being such as relieving body pain and stress, and leads to better socialization among friends and (c) higher prevalence of problematic drinkers among those who were illiterate, have history of tobacco use, living alone (unmarried/divorced), and consumption in wine shop/bar/street as opposed to home (Eshwar et al., 2019). 


\section{Percentage of Men and Women who drink Alcohol in India}

Variation of Alcohol consumption by states and gender

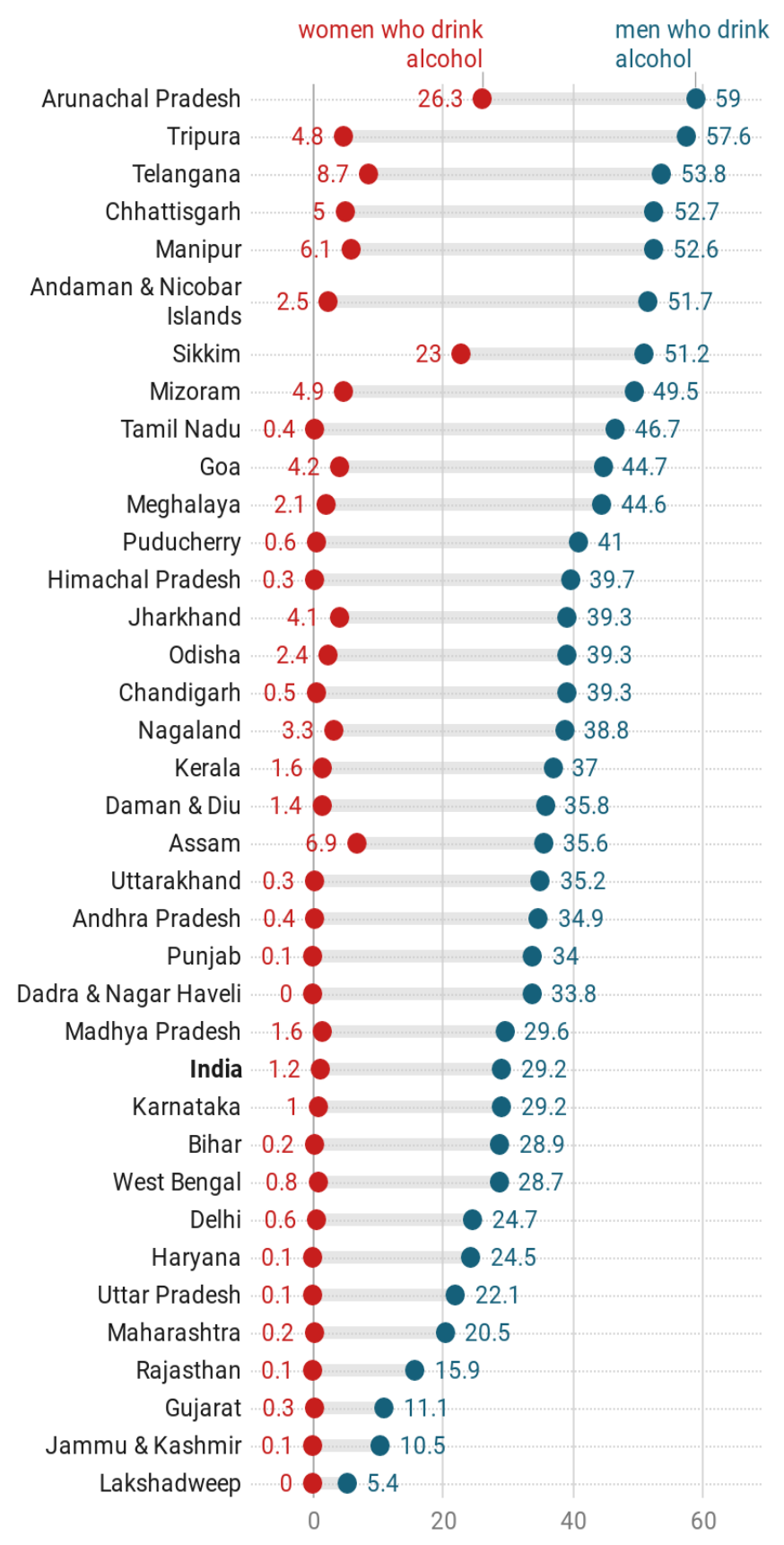

Chart: Shivakumar Jolad • Source: NFHS-4 2015-16 • Created with Datawrapper

Figure 1: Variation in Alcohol consumption in India by State and Gender, Data source: National Family Health Survey 20516, India.

Alcohol and Public Health 
Excessive and/or harmful consumption of alcohol has profound public health impacts. Studies have warned of multiple medical complications (depending on the level and frequency of use) such as Gastrointestinal disease (including alcoholic liver disease) , Cancer (Breast, oral, and oesophageal), muscular changes (muscular atrophy), neurological complications ( blackouts, blurred vision, impaired memory and slower reaction times), and psychiatric complications (anxiety, depression, and suicide) (Eshwar et al., 2020). Of the 260,000 alcohol-related deaths identified by the WHO Substance Abuse Report of 2018, liver cirrhosis $(140,000)$, road accidents $(930,000)$, and cancer $(31,000)$ are major causes.

Despite India's growing alcohol use and the lucrative excise duties, the Indian government has also adopted a National Target requiring 10\% relative reduction in alcohol use by 2025 . The WHO's Global Strategy to Reduce the Harmful Use of Alcohol (2010) recommends that states "regulate the commercial or public availability of alcohol through laws" to "prevent easy access to alcohol by vulnerable and high-risk groups" (WHO, 2010). Is current alcohol policy serving the Indian state's self-professed public health goals?

\section{Alcohol and Domestic Violence}

The National Family Health Survey (NFHS-4) 2015-16, (India report) presents grim numbers regarding the linkage between alcohol and Domestic Violence (DV). 71\% of women with husbands who often got inebriated with alcohol have experienced physical or sexual violence as compared to $22 \%$ of women with husbands who did not abuse alcohol (IIPS and ICF, 2017).

Alcoholism might not be the sole cause of Domestic violence, as DV is also reported in homes where the husband was reported nonalcoholic. Further, there are multiple determinants of spousal violence(Mahapatro et al., 2012) including level of education of husbands and wives, age of the woman, religious affiliation and caste and type of occupation. But insofar as state permission for growing alcohol sales lowers atleast one of thresholds for domestic violence, it presents important public health, equity and gender parity considerations that cannot be ignored during policy formulation. 


\section{Husband Alcohol use and spousal violence in India}

Based on NFHS-4 Data 2015-16

Does Not drink
Drinks, but never gets drunk
Gets drunk sometimes
Gets drunk often

Chart: Shivakumar Jolad • Source: National family Health Survey-4, India • Created with Datawrapper

\section{A stratified society drinks unequally}

India's social stratifications result in unequal drinking patterns and the NFHS-4 (2015-16) records some interesting disparities in this regard. There is stark gender, caste, and regional disparity in drinking. In the 15-49 year age group, Scheduled tribe men (41\%) and women (6.5 \%) drink more than other groups. Among major religions, Christian men (43\%) and women (4\%) drink more than all others while Muslim (0.1\%) and Jain women (0.2\%) drink the least. There is also considerable regional variation in alcohol consumption. North-eastern states, especially Arunachal Pradesh (59\% men, 26.3\% women) and tribal states like Chhattisgarh (52.7\%, 5\%) and Jharkhand (39.3\%, 4.1\%) have the highest alcohol consumption, while Jammu and Kashmir (10.5\%M 0.1\%F ), Gujarat (11.1\%, 0.3\%), and Rajasthan (15.9\%, 0.1\%) have the lowest.

\section{Historical legacy of consumption, taxation, and regulation}

Alcohol has a complex history in the subcontinent and its study is essential to provide the moorings for a new policy framework. Documented socio-cultural history of fermented and distilled alcohol from fruits, grains and flowers in India can be traced even in the Vedic literature. The social sanction for alcohol consumption was restricted by the Varnas (Sharma et al., 2010). While Brahmins were totally forbidden from drinking alcohol, Khastriyas used to drink both Soma ('celestial nectar') and Sura ( beer manufactured from rice meal, barley). Sura was more common among the general populace. Lower castes usually consumed cheap 
distilled local spirits. On the other hand, Buddhism and Jainism strongly condemned the use of alcohol.

\section{Percentage of people who drink alcohol}

Drinking in India by education. religion, caste, and wealth

\begin{tabular}{|c|c|c|}
\hline \multicolumn{3}{|l|}{ Women Men } \\
\hline & Women & Men \\
\hline No Schooling & 2.6 & 40 \\
\hline$<5$ years complete & 1.5 & 35.7 \\
\hline 5-7 years complete & 0.7 & 35.3 \\
\hline 8-9 years complete & 0.6 & 27.6 \\
\hline $10-11$ years complete & 0.5 & 24.7 \\
\hline 12 or more years complete & | 0.6 & 24.3 \\
\hline \multicolumn{3}{|l|}{ Religion } \\
\hline Other & 11.5 & 43.3 \\
\hline Christian & 4 & 42.8 \\
\hline Sikh & 0.1 & 33.8 \\
\hline Buddhist/Neo-Buddhist & 1.4 & 32 \\
\hline Hindu & 1.3 & 31.6 \\
\hline Muslim & 0.1 & 11.3 \\
\hline Jain & 0.2 & 15.5 \\
\hline \multicolumn{3}{|l|}{ Caste } \\
\hline Scheduled tribe & 6.5 & 41.3 \\
\hline Scheduled caste & 0.9 & 36.3 \\
\hline Other backward class & 0.7 & 28.5 \\
\hline Other & 0.5 & 21.1 \\
\hline Don't know & 1.5 & 26 \\
\hline \multicolumn{3}{|l|}{ Wealth index } \\
\hline Lowest & 2.9 & 35.4 \\
\hline Second & 1.4 & 29.9 \\
\hline Middle & 1 & 30 \\
\hline Fourth & 0.6 & 27.8 \\
\hline Highest & 0.6 & 25.1 \\
\hline
\end{tabular}

Figure 3: Social Stratification of Drinking in India; Data Source: National Family Health Survey-4: 2015-16

In the Mauryan period when much of India came under a central rule, Chanakya's Arthashastra describes the need for "regulation of alcohol production and sales, including directions for the establishment of drinking places". Later, Charaka (uncertain period from 
100 BCE - 200 CE), in his work Charaka Samhita recognised the medicinal use of alcohol and called for its moderate use. He made a clear distinction between moderate versus excessive drinking, noting that moderation is "pleasing, digestive, nourishing and preserves intelligence" (Boesche , 2003). It is precisely this moderation that India's current alcohol policy should seek as its end goal rather than completely paternal and outright prohibitioncentric approaches.

The Islamic rule in India shows ambivalent liquor regulation depending on the king's personal choice and preferences. While the Quran specifically forbids alcohol, wine remained part of court life- especially during the Mughal rule. The rulers (barring few exceptions like Aurangazab) usually did not interfere with consumption by Hindus and Muslims (Sharma et al., 2010).

\section{Colonial-era commodification}

Alcohol production, consumption and state regulation acquired a new dimension during British colonial rule in India. Till then, liquor production was largely an affair of small communities. The British liquor policy was guided, "avowedly, by the twin objects of generating revenue on the one hand and checking intemperance among people towards safeguarding their morality, on the other" (Saldanha, 1995). The Abkari Act of 1878, barred toddy extraction without permission and license and shifted the mahua spirit from traditional decentralized farm distillation to central distillation. The liquor produced at the distillery was taxed, changing the alcohol taxation from revenue to excise (Saldanha, 1995). The public auctioning of liquor licences, led to the rapid increase in government distilleries and the replacement of traditional low alcohol content alcoholic beverages by industrial scale liquor with higher alcohol content. This new commodification of liquor production and heavy taxation led to a surge in the revenue collections (Hurst, 1889). Towards the end of the colonial period, excise duty on liquor came second only to land revenue, and alcohol emerged as a commodity essential to Indian economic nationalism and industrialization (Bhattacharya, 2017).

\section{Prohibition in post-colonial India- A failed policy}


Driven by Gandhian values, many states in India imposed Prohibition laws postIndependence. The Bombay Prohibition Act, 1949 banned the manufacture, transport, sale, purchase, and consumption of alcohol in the State of Bombay (Khodaiji, 2017). Almost one fourth of India was under prohibition law in 1954. By the mid-1960's most states repealed or relaxed prohibition law due to shortfall in revenue, illicit brewing and hooch tragedies. Only Gujarat has a continuous history of Prohibition from its inception in 1960 to the present. Bihar is the latest state to have Introduced Prohibition, albeit with a draconian Bihar Prohibition and Excise Act 2016. Additionally, Nagaland, Mizoram, and Manipur (partially) have prohibition in effect now (MK, 2015; Eashwar et al., 2020) (See Figure 4).

Prohibition attempts has historically been a failure in many countries across the world. In US, the Prohibition imposed from 1920-33, to reduce crime and corruption and solve social problems, led instead to an increase in bootlegging, alcohol poisoning, and decrease in state revenue. It promoted many drinkers to switch to more dangerous substance abuse of opium, and cocaine (Thornton, 1991). The same adverse effects have been in India's prohibition states. It has encouraged rampant bootlegging, hooch tragedies, and has encouraged other substance abuse. In the state of Bihar, the penalty for getting caught drinking is Rs 50,000 (\$750), 5-10 times the monthly income of the poor, or three months in jail. An even more stringent second-time fine of Rs $100,000(\$ 1,300)$ and 5 years in jail, can ruin the entire family (Business Times, 2018). As of 2020 , 260,000 people have been booked under its Prohibition Act 2016 while 210,000 cases are pending and about 8,000 are in Jail. Most of the accused are poor and marginalised, who can't post bail or afford lawyer fees (Ramashankar and Khan, 2020). With the earning member in jail, families are left to feed themselves and children are unable to continue schooling. There are reports that just a year after the ban, Bihar had an alarming rise in substance abuse and bootlegging.

Along with Prohibition, Gujarat enacted the Prevention of Anti-Social Activities Act (PASA) in 2017 to curb bootlegging. In spite of its stringent penalties, prohibition violations continued to raise-- from 170,000 in 2017 to 210,000 in 2018, with an estimated 800,000 pending cases in Gujarat courts (Ramashankar and Khan, 2020). In Ahmedabad, the Chhara community, who have been historically discriminated against as one of the Denotified and Nomadic Tribes 
(DNTs), are still tagged as "habitual offenders," stigmatizing the whole community as criminals. The Chhara women, a sizable number of whom brew liquor due to economic hardships and social norms against working outside, remain at the receiving end of police violence and harassment (Da Costa, 2016).

\section{Alcohol Prohibition and Curbs in Indian States}

As of 2020

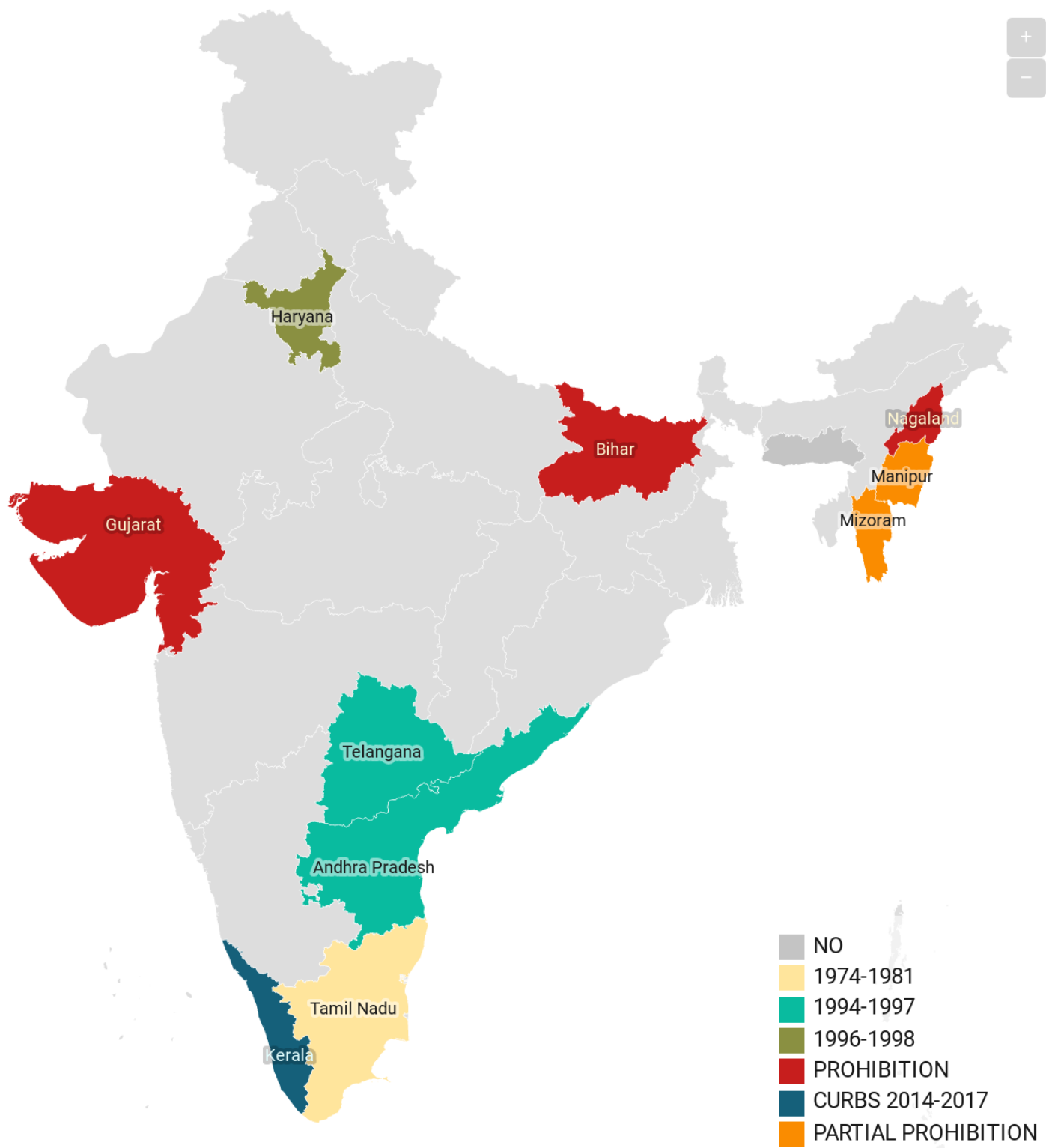

Map does not show bifurcation of Jammu and Kashmir in 2019

Map: Shivakumar Jolad $•$ Source: Public Soucre $\cdot$ Created with Datawrapper

Figure 4: State and history of prohibition and alcohol curbs in India; Inputs from: A brief history of prohibition in India, https://www.opindia.com/2017/04/a-brief-history-of-prohibition-in-india/

Alcohol Paternalism : moving from old to new, hard to soft 
The legacy of Alcohol Commodification, Taxation, and Prohibition in various degrees followed from colonial times to the current policies has resulted in an 'old and hard' state paternalism based on moralistic grounds, with little regard for individual liberty, and consumption patterns in a stratified society. The results of such policies have fallen well short of achieving the desired goals of moderation, preventing alcohol abuse, domestic violence, and reduced health consequences of addictive behaviors. Here we review the different types of paternalism that provide the philosophical-ethical bases for Indian alcohol policies, and suggest policies based on new and soft versions of paternalism to achieve desired ends.

Paternalism is the notion that allows the government to "restrict the choices of individual citizens for their own good" (Dworkin, 2011). For an act to be paternalistic, it must involve interference in a person's freedom (choice of opportunity to choose) with an expressed objective of enhancing the target person's welfare without his/her consent (New, 1999). Paternalism's more stringent version, known as hard paternalism, is premised on the belief that the state reserves the legitimate right to interfere in a person's actions, despite the actions being undertaken willingly and with full knowledge, including of the deleterious consequences of said actions (Pope, 2005). Examples of hard paternalism include higher taxes on perceived unhealthy food in an attempt to discourage consumption thereby lowering obesity rates, (Hoffer and Nesbit, 2018), high cigarette taxes to dissuade smoking (Lucas, 2011) and "sin taxes" on alcohol and gambling (Kapeliushnikov, R. , 2015).

Prohibition is one of the strictest forms of paternalism (Thomas \& Buckmaster, 2010): it has traits of hard paternalism. The state intervenes in person's drinking, even when that person is acting voluntarily and knowledgeably and uses a moral corruption argument to justify it. India's 'hard' paternalism has to be understood in tandem with a version of paternalism known as 'old' paternalism. In this sort of paternalism, the state understands its role as a benevolent "caregiver" and "enforcer of values" with the obligation to get citizens to adhere to patterns of behavior that are often predicated on religious and moral principles held by state policymakers (Kapeliushnikov, 2015). The deeply-held assumption is that the state knows what is good for the welfare of its citizens than they do themselves. (Kapeliushnikov, 2015) 
In India, the imposition of nationwide prohibition following independence is a good example of Gandhi's moral-religious view of alcohol as a societal evil. The persistence of total prohibition in the Indian state of Gujarat (Gandhi's birth state) to this day, highlights the continuing influence of Gandhian values on state alcohol policy. This influence is part of a broader, systemic state intrusion into individual autonomy, drawing on moral beliefs. Section 377 of the Indian Penal Code criminalizing homosexuality and Section 497 of the Indian Penal Code criminalizing adultery, both recently struck down by courts, are other examples of such morality-influenced, old-paternalism.

Soft-paternalism, also known as "autonomy-oriented paternalism"(Fateh-Moghadam, B., \& Gutmann, T. (2014)) disagrees with hard paternalism's deep intrusion into an individual's autonomy (freedom of choice) and advances a less intrusive approach towards shaping individual choices which will enhance their self-perceived welfare. Eschewing old-hard paternalism's 'heavy-handed' approach, soft paternalism favors calibrated state intervention which respects the autonomous decisions made by competent persons, ensures individual autonomy and freedom to make choices while shaping available choices in a manner that enhances the self-perceived welfare of citizens.

Soft paternalism's 'light footprint' approach that emphasizes creatively shaping citizen choices through laws resting on a secular foundation also dovetails with New Paternalism, a more recent variant of Paternalism which rejects old paternalism's coercive approach. Instead, the "subjective preferences of individuals" including enabling them to achieve what they desire is taken as the "normative standard" (Kapeliushnikov, 2015). Examples include a voluntary "self-exclusion list" for compulsive gamblers that results in arrest and earningconfiscations when violated (Fateh-Moghadam \& Gutmann, 2014).

Libertarian paternalism, a recent version of soft paternalism that places even greater emphasis on minimizing erosion of individual autonomy reckons that state intervention is only justified when the person being interfered with is "acting voluntarily and knowledgeably" (Dworkin,2011). 
The core assumption of libertarian paternalists is that conscious efforts by Institutions, both government and private, can steer people's choice in directions that will improve their lives, as judged by themselves. Behavioural economists have shown that small nudges introduced through clever choice architecture can alter people's behaviour in a predictable way without forbidding any options. Examples include default option for retirement savings in salary deduction, placement of healthy food in the front row of school canteen, and educational campaign(Thaler \& Sunstein, 2009). This could serve as a useful philosophical approach under which a new alcohol policy can be proposed .

\section{Limitations of hard paternalism in India}

Paternalistic arguments for increasing taxation on alcoholic beverages are based on the premise that people are "incapacitated by addiction or because they suffer from failures of rationality". Higher taxes, it is presumed, will reduce Alcohol consumption, and may actually benefit the poor by encouraging them to give up their habit by attaching a punitive, price signal to alcohol. However, this is not substantiated by empirical evidence in India that has shown alcohol taxes to be largely inelastic. A recent study by Santosh Kumar, estimated the price elasticity of alcoholic beverages in India (Kumar, 2017). The Price Elastic Demand (PED) for beer, country liquor, and spirits are $-0.330,-0.46$, and -0.14 respectively, indicating the increase in liquor price by $1 \%$ leads to $0.46 \%$ for country liquor, $0.33 \%$ for Beer and only $0.14 \%$ for spirits.

Alcohol taxation in India currently follows a one size fits all approach. Across-the-board hightaxation is easy to implement and aims to decrease harmful alcohol consumption by uniformly penalizing drinkers at all levels. But drinkers in socially stratified India are not homogeneous and differ considerably in their level of drinking including (a) Casual drinkers (occasional drinkers, (b) problem- drinkers (drink frequently and more than what they intend to) and (c) Alcoholics -- usually binge drinkers and alcohol abusers. Casual drinkers are not addicts- and cause no harm to others, and their action cant be considered irrational.

Heavy taxation (even on non-distilled low alcohol drinks) poses a significant burden on lowincome families. It disproportionately affects the poor, creating a moral hazard as it forces 
them to shift to high alcohol content, distilled country spirits posing greater health risks and undermining the goal of improving public health.

\section{Pragmatic Alcohol policies for the 21st Century}

The current understanding of alcohol as solely a commodity, ripe for high taxation is at odds with the eclectic history of alcohol in the subcontinent with its spells of regulation, deregulation, prohibition and commodification. A 21st century alcohol policy must aim to find a new basis, other than commodification to meet the multiple goals of buoyant support for improvement of public health, enhancement of gender parity, respect for individual choice, promotion of moderation in drinking and balancing public finances. Such a policy focused on moderation should incentivize a substantial proportion of Indians to reduce their alcohol consumption to a moderate level.

The 'new-soft' paternalist beliefs summarized in this paper are better compatible as the foundation for a new, more progressive alcohol policy in a liberal democracy that prioritizes individual rights than India's current 'old-hard' policies which allows for an untrammeled state intrusion into citizen's lives, while still producing sub-optimal outcomes. New-soft policies better align with the harm principle of English philosopher John Stuart Mill (J S Mill, 1859) and his core convictions that limiting people's liberty is justifiable only in few circumstances such as preventing harm to other people (harm principle, John Stuart Mill). Even the deployment of 'new-soft' paternalistic policies should be conditioned on the state being able to cross a high threshold of justification to intervene and constrict individual autonomy. We propose a set of 'new-soft' paternalistic policies which satisfy the aforementioned threshold.

- Tax rationalization: Taxation is the 'hard' part of a spectrum of policies that fall under soft paternalism. However, this form of taxation avoids the punitive, across-the-board taxation approach of hard paternalism. The nature of the design of taxes comprising soft paternalistic policies takes note of the relative price-inelasticity of alcohol consumption and the moderate ability of high, 'old-hard' taxes to change 
consumption behaviour. We recommend that states create an optimal differential taxation system as a monetary incentive for people to shift from high concentration to lower concentration alcohols, causing a fraction of the populace to prefer going in for beer or wine rather than hard-liquor. Tax on mild alcoholic drinks with less than $5 \%$ ABV can be brought under Goods and Services Tax (GST). Special tax exemptions can be given to wines made from local grapes, and fruit wines (subjected low $A B V$ ) can promote moderation, improve local economy, and preserve local culture. We recommend a progressive taxation system which creatively uses the difference in alcohol content between hard liquors and low concentration alcohols (and the corresponding differential public health impacts) and calibrates the price signal accordingly.

- Legal and Judicial reforms: Prohibition laws, with their low thresholds for deployment have disproportionately affected the poor, caused lengthy pendency periods for under-trials and affected livelihoods of the families of accused violators. Prohibition, has no place in a modern state as it is a non-secular, inegalitarian, and is based on strong state interventions that severely constrict individual autonomy. Our 'new-soft' approach combines the dire necessity to reorient the criminal justice system with the recognition of persistence of religious values (to varying degrees) as a design constraint for policies in prohibition states in the near and medium term.

The approach calls for sorting of cases into minor and serious violations, amnesty for minor violators, proportionate punishment for illegal producers, distributors and consumers of alcohol in time-bound trials (in specially constituted fast-track courts, if necessary). The aforementioned policies should be construed as incremental 'conduit' policies towards a more fundamental, transition towards decriminalization of consumption and eventually rollback of prohibition. Calibration of punitive signals is as essential as calibration of price signals to prevent excessive state intervention eroding individual autonomy, reducing the case burden on the judicial system and reducing the opportunity cost of hearings on minor violations crowding out those for major ones. 
- Break the License-raj in alcohol production: India's old-hard paternalistic policies have resulted in a harsh regulatory environment designed to make it difficult for private alcohol producers to operate while also maximizing tax revenues through excise duties. The regulatory 'license-raj' requires large private players such as United Spirits up to 200,000 state-granted approvals, licenses and permissions to operate every year (Kazmin , 2016-Oct 9). Such a harsh regulatory threshold is problematic from a 'new-soft' paternalistic standpoint as it represents excessive state intervention and prevents new small and medium-scale aspirants selling low-alcohol content spirits from entering the market. We propose streamlining of permits and approval for large and small companies willing to enter the beer and wine bracket. The assumption being that an increase in such companies would automatically add momentum to their marketing and public relations strategies to promote low-alcohol content beer and wine, with the attendant lower public disease burden for the Indian state while not compromising tax revenue.

To lower costs while maintaining quality and to broaden the base of the alcohol economy to include more beer and wine-producing small players, the government could consider treating alcohol as a product of small and medium-scale enterprises, enabling conditions for local brewers to brew and sell alcohol, with regulations tailored to balance public health and public finances. But these regulations should not lead to a bureaucratic quagmire for the small scale brewers.

- Nudging India to moderation: Libertarian paternalism with its nudges can influence the choice of affected parties in a way which makes the parties better off while preserving their individual choice (Thaler and Sunstein, 2012). Here we propose nudges such as clever social messaging and design changes to reduce alcohol consumption and abuse.

Awareness through messaging: People are easily influenced by others behaviour : they succumb to peer pressure, prefer social-conformity, and follow the herd. Social influence can be effectively used to nudge people's behaviour to prevent alcohol abuse. Thaler and Sunstein provide an example : A survey by Harvard School of Public 
health showed that most students believe alcohol abuse is far more prevalent than it actually is (mainly due to perceptions shaped by availability heuristic). An educational campaign by Montana state in US exploited this fact and used a messaging campaign based on actual prevalence, which, as subsequent research showed, had a significant effect on reducing binge drinking. Another work by Taylor et al. found that, ranking how much people drank relative to other peers, led to excessive drinkers asking for expert recommendations on reducing alcohol consumption (Taylor et al., 2015).

The importance of strategic communication will be paramount in any such endeavor and we suggest clever messaging based on a sound understanding of consumption by a pattern by age group, gender, education, and social strata. Several such examples exist in the Indian context such as the Beti Bachao, Beti Padhao campaign and the reframing of toilets as "izzat ghars" to help the message of toilet-usage resonate better with rural India.

We recommend that the state government should mandate that a certain minimum fraction (say 5\%) of the revenues from taxes on alcohol be devoted to creating messaging tailored to different regional and social context, positive messaging highlighting the benefits of moderation and negative messaging with the dangers of alcoholism and domestic violence.

Design Nudges: Simple nudges based on design changes in production and distribution of alcohol can reduce alcohol abuse. Behavioural studies have shown that the size of the plate can reduce the calorie intake and mindless eating (Wansink and Van Ittersum, 2007). Along the same line, several nudges have been suggested to reduce the alcohol consumption such as reducing the size of glasses, making them tall and slender (which gives an illusion of drinking larger quantity), serving low alcohol content drinks (such as wine and beer) as default etc (Hansen PG, n.d). For example, altering the unit size of Alcoholic beverages from the current sizes: $750 \mathrm{ml}, 375 \mathrm{ml}$ and $180 \mathrm{ml}$ bottles, to the only $600 \mathrm{ml}, 300 \mathrm{ml}, 150 \mathrm{ml} \mathrm{ml}$ can give a false perception of full drink but actually consuming less. Placement changes in shops can also affect alcohol sales. In pubs and bars, putting low alcohol beverages in front and in big fonts, act as 
a nudge to choose the former. Making breath analyzers widely available in pubs and bars and mandating breath tests before entry and exit of pubs can alter the behaviour of drinking.

\section{Concluding remarks}

In this paper, we have reviewed the history of alcohol consumption and taxation in India, and highlighted the nature of current alcohol policies across states in India and its colonial lineage. We have also discussed the complex pattern of alcohol consumption with wide variations across region, religion, caste, education and socio-economic strata. Our primary argument is that current alcohol policies (prohibition, excessive, across-the-board taxation, and regulation) are lately paternalistic in nature and fall under old- hard paternalism based on moral and religious sentiments.

We have highlighted the need to follow a modern programmatic approach consisting of a combination of 'new-soft' paternalistic policies (including its recent avatar of Libertarian paternalism) that balance people's right to choose, maximize individual autonomy and ensure more egalitarian welfare as perceived by people. Such policies involve tax-rationalization which rejects across-the-board high taxation, legal and judicial reforms which modify 'oldhard' prohibition's severely constraining laws and reduce pendency rates based on 'new-soft' paternalism. We also recommend market reform to allow entry of small-medium scale enterprises and nudges based on design and messaging changes to shift towards moderation.

India's current 'permit but don't openly promote' alcohol policy is succeeding in terms of ensuring consistent tax revenues but is failing to minimize its public health and gender security fallout. A strategy of total prohibition is a coercive approach which restricts individual choice and is incompatible with liberal democracy .

On the other hand, complete de-regulation and permissiveness is also not a viable option given the enormous public health and gender parity ramifications. What's required is a 'middle-path' policy with an incentive structure that 'nudges' or induces people towards 
moderation while also leaving the option for others who do not wish to benefit from the aforementioned incentive structures to opt out.

As we close, we wish to add that Alcohol should be treated as a socio-cultural product rather than just a commercial commodity. Policymakers must acknowledge India's eclectic alcohol consumption and regulation history and the influence of religious and moral values in policies pertaining to prohibition and permissiveness. They must also accord importance to crucial considerations such as implications for women's safety and profound social stratifications that result in unequal drinking patterns. Such a broad view can help policymakers recognize the profound interconnectedness of alcohol's myriad impacts and prevent policymaking from getting trapped in dilemmas which the Indian state currently finds itself in.

\section{Bibliography:}

1. Ambekar A, Agrawal A, Rao R, Mishra AK, Khandelwal SK, Chadda RK on behalf of the group of investigators for the National Survey on Extent and Pattern of Substance Use in India (2019). Magnitude of Substance Use in India. New Delhi: Ministry of Social Justice and Empowerment, Government of India. Available from : https://tinyurl.com/MagSubUselndia2019

2. Bhattacharya, N. (2017). The Problem of Alcohol in Colonial India (c. 1907-1942). Studies in History, 33(2), 187-212. URL: https://tinyurl.com/Bhattacharya2017

3. Boesche R. (2003). The first great political realist: Kautilya and his Arthashastra. Lanham: Lexington

4. Business Times. (2018, July 23). 'Bihar liquor ban: Nitish Kumar govt amends Prohibition Bill, imposes Rs 50,000 fine for first time offenders.' URL: https://tinyurl.com/yb9kkcrt Accessed on 15 August 2020

5. Dworkin, G. (2011). Paternalism. Stanford Encyclopedia of Philosophy. Available from http://plato.stanford.edu/entries/paternalism. (Accessed on 19 August 2020).

6. Eashwar, V., Umadevi, R., \& Gopalakrishnan, S. (2020). Alcohol consumption in IndiaAn epidemiological review. Journal of family medicine and primary care, 9(1), 4955. https://tinyurl.com/Eashwar2020 
7. Global Health Observatory. (2020). Total alcohol per capita (15+ years) consumption, in litres of pure alcohol. WHO. Available from : https://tinyurl.com/GHO2020

8. Goldstein Research (2020, May 15): India Alcoholic Beverages Market Trends, Growth and Forecast Analysis 2020-24. URL:

https://tinyurl.com/GoldsteinIndiaAlcohol

9. Government of Maharashtra Excise Department. (2019). Current Duty and Fee Structure. Mumbai: Government of Maharashtra. URL:

https://tinyurl.com/MaharashtraExcise

10. Gupta, P. C., Saxena, S., Pednekar, M. S., \& Maulik, P. K. (2003). Alcohol consumption among middle-aged and elderly men: a community study from western India.

Alcohol and Alcoholism, 38(4), 327-331

11. Hansen. P G (n.d), 7 Nudges To Avoid Adult Binge Drinking At X-mas, INudgeYou, Available from https://tinyurl.com/HansenNudge (Accessed on 19 August 2020)

12. Hoffer, A. J., \& Nesbit, T. (Eds.). (2018). For Your Own Good: Taxes, Paternalism, and Fiscal Discrimination in the Twenty-first Century. Mercatus Center, George Mason University. p 308 . URL: https://tinyurl.com/Hoffer2018

13. Hurst, JF, (1889) The Temperance Question in India. The Century, vol. 38, issue 3. URL: https://tinyurl.com/Hurst1889

14. IIPS and ICF. (2017). National Family Health Survey (NFHS-4), 2015-16. Mumbai: IIPS. (pp 570). Retrieved from https://tinyurl.com/IIPS2017

15. Kapeliushnikov, R. (2015). Behavioral economics and the 'new' paternalism. Russian Journal of Economics, 1(1), 81-107.URL: https://tinyurl.com/Kapeliushnikov2015

16. Kazmin . A, (2016, Oct 9), 'Drinks industry: India's battle with the bottle Prohibition threatens one of the biggest untapped markets in the world', Financial Times. URL: https://tinyurl.com/KazminFT2016. Accessed on 15 August 2020

17. Khodaiji, D. M. (2017, March 20). 'Parsis and prohibition.' Parsi Times. Available at https://parsi-times.com/2017/03/parsis-and-prohibition/ .Accessed on 17 August 2020.

18. Kumar, S. (2017). Price elasticity of alcohol demand in India. Alcohol and alcoholism, 52(3), 390-395 
19. Lucas, J. (2011). Saving smokers from themselves: The paternalistic use of cigarette taxes. University of Cincinnati Law Review, Vol. 80 (693)

\section{https://papers.ssrn.com/abstract=1942068}

20. Mahapatro, M., Gupta, R. N., \& Gupta, V. (2012). The risk factor of domestic violence in India. Indian journal of community medicine, 37(3), p 153. URL:

\section{https://tinyurl.com/Mahapatro2012}

21. Mill, J S and Alfred A. Knopf (1993). On liberty and utilitarianism, New York, p. 80.

22. New, B. (1999). Paternalism and public policy. Economics \& Philosophy, 15(1), 63-83

23. Nidheesh.MK, (2015, November 30). How Indian states have fared in banning alcohol? Livemint. Available from https://tinyurl.com/MKNLivemint2015 (Accessed on 19 August 2020)

24. Pope. T 2005. 'Is public health paternalism really never justified? A response to Joel Feinberg', Oklahoma City University Law Review, 30:1, 2005, p. 121. Cited in Thomas \& Buckmaster, (2010) Paternalism in social policy when is it justifiable? Parliament of Australia. https://tinyurl.com/PopeAU2015

25. Ramashankar and Khan. S. (2020, Feb 12). 'The social cost of Prohibition in Bihar and Gujarat' Times of India. https://tinyurl.com/y9hdrfye. Accessed on 18 August 2020.

26. Reserve Bank of India. (2019). STATE FINANCES : A STUDY OF BUDGETS. Mumbai: Sangita Misra for the Reserve Bank of India.

URL: https://tinyurl.com/RBIStateFinance2019

27. Rizzo, M. J., \& Whitman, D. G. (2009). Little brother is watching you: New paternalism on the slippery slopes. ARIz. L. REV., 51, 685.

URL: https://tinyurl.com/Rizzo2019

28. Saldanha, I. M. (1995). On Drinking and 'Drunkenness': History of Liquor in Colonial India. Economic and Political Weekly, 2323-2331. URL:

\section{https://tinyurl.com/Saldania1995}

29. Sharma, H. K., Tripathi, B. M., \& Pelto, P. J. (2010). The evolution of alcohol use in India. AIDS and Behavior, 14(1), 8-17. URL: https://tinyurl.com/Sharma2010

30. Sharma, H (2020, May 14). 'Explained: Why liquor sales matter to states'. The Indian Express. Retrieved from https://tinyurl.com/IEMay1420.Accessed on 18 August 2020. 
31. Taylor, M. J., Vlaev, I., Maltby, J., Brown, G. D., \& Wood, A. M. (2015). Improving social norms interventions: Rank-framing increases excessive alcohol drinkers' information-seeking. Health psychology, 34(12), 1200. Also quoted in : Vlaev.I. (2016) How to start nudging people to drink less alcohol. The Conversation. Available at https://tinyurl.com/TaylorConversation2015. (Accessed on 20 August 2020)

32. Thaler, R. H., \& Sunstein, C. R. (2009). Nudge: Improving decisions about health, wealth, and happiness. Penguin.

33. Thornton, M. (1991). Cato institute policy analysis no. 157: Alcohol prohibition was a failure. Washington DC: Cato Institute. URL:

https://www.cato.org/publications/policy-analysis/alcohol-prohibition-was-failure

34. TOI (2020, May 6). 'Lockdown 3.0: Moolah flows into state coffers as liquor sale.' The Times of India, p. A4. Retrieved from https://tinyurl.com/TOIMAY0620 .Accessed on 20 August 2020.

35. Wansink, B., \& Van Ittersum, K. (2007). Portion size me: downsizing our consumption norms. Journal of the American Dietetic Association, 107(7), 1103-1106.

36. World Health Organization. (2010). Global strategy to reduce the harmful use of alcohol. URL: https://tinyurl.com/WHO-2010

37. World Health Organization. (2019). Global status report on alcohol and health 2018:Country Profile, India. URL: https://tinyurl.com/WHOAlcohollndia 